\title{
Cytodiagnosis of a Testicular Epidermoid cyst in a Young Male: A Rare Entity
}

\author{
Dilip Kumar, Anupama Arya, Shruti Mahawar, Poonam Das and Nitin Dayal \\ Institute of Lab Medicine, Max Super Speciality Hospital, Saket, New Delhi, India
}

\section{ABSTRACT}

Intratesticular epidermoid cyst is a rare benign lesion of testis. It is important to distinguish this benign lesion from malignant testicular tumor. This is a case report of a 18yr old patient who presented with a mass in the left testis. His ultrasound showed typical onion skin appearance and tumour markers were within normal limits. Subsequently FNAC was performed which showed anucleated clumps of squamous epithelial cells admixed with the native testicular cells, thus diagnosis of testicular epidermoid cyst was made. Cytology along with sonographic findings provide rapid diagnosis and patient can be relieved of unnecessary anxiety.

\section{Keywords: Epidermoid Cyst, Testis, Anucleated Squamous Epithelial Cells}

\section{IntroductIon}

Testicular epidermoid cyst is an infrequent tumor, accounting for $1 \%$ of all testicular masses occurring in mid adulthood ( $2^{\text {nd }}$ to $4^{\text {th }}$ decade). Such lesion is benign entity without any malignant potential. Teratoma is one of the important differential diagnosis, however cytology along with classical sonographic appearance rules out the same. An 18 year old boy presented to the OPD with complaint of swelling in the scrotum. Serum Beta HCG and AFP were found to be within normal limits. USG revealed classical onion skin appearance. Cytology showed presence of anucleated clumps of squamous epithelial cells along with normal cellular component of testis. Cytology along with sonographic findings provides early diagnosis of the lesion and thus unnecessary Orchidectomy can be avoided.

\section{Case Report}

A 18 year old boy presented to the out patient department with the complain of pain and swelling in the scrotal region. On physical examination, the swelling was palpated in the left upper part of the scrotum .The swelling was $1 \mathrm{x} 1 \mathrm{~cm}$, firm, tender and not fixed to the skin. The skin over the swelling appeared normal. There was no history of trauma or fever. The right testis appeared normal.

On sonographic examination, the left testis measured approximately $4.4 \times 2.1 \times 2 \mathrm{~cm}$. A lesion was seen in left testis measuring approximately $1.7 \times 1.1 \times 1.9 \mathrm{~cm}$ in size giving rise to a characteristic onion skin appearance. A subsequent Doppler showed mild intralesional vascularity in the lesion. The right testis and both the epididymus was found to be normal in size and echotexture. USG abdomen was normal. A Contrast enhanced CT scan of the testis revealed a focally enhancing left testicular lesion without any significant retroperitoneal/ inguinal lymphadenopathy. Serum tumour marker, Beta-HCG was less than $0.2 \mathrm{mIU} /$ $\mathrm{ml}$ (normal- $0.5-2.67 \mathrm{mIU} / \mathrm{ml}$ ) and serum AFP was $1.20 \mathrm{ng} /$ $\mathrm{ml}$ (normal- 0-9 ng/ml), which ruled out the possibility of it being a teratoma.

FNAC was performed with $22 \mathrm{G}$ needle after giving cord block with $2 \%$ lignocaine. Two passes were made and on each occasion, the needle was manipulated in different directions. A clear aspirate was obtained on both the occasions. The slides were air dried and wet fixed in 95\% alcohol. The air dried slides were stained with May Grunwald Giemsa stain and the wet fixed slides were stained with Papanicolaou stain. On microscopic examination, anucleated clumps of squamous epithelial cells were seen along with normal spermatogenetic cells including immature germ cells, sertoli cells and spermatid heads. No cells of mesodermal or endodermal origin were seen. No evidence of parasite or malignancy was observed. Thus cytological diagnosis of "Testicular Epidermoid Cyst" was suggested in correlation with radiological findings.

\section{Discussion}

FNAC has become a preliminary preoperative diagnostic tool for diagnosis of any tumour, whether benign or malignant. It has an inevitable role in preoperative diagnosis of a testicular epidermoid cyst as it surpasses an unnecessary orchidectomy in a patient .

Testicular epidermoid cyst is an uncommon entity, constituting $1-2 \%$ of testicular mass lesion. ${ }^{[1]}$ These are keratin-filled intratesticular cysts, which generally present as solid appearing testicular masses. These are benign and 


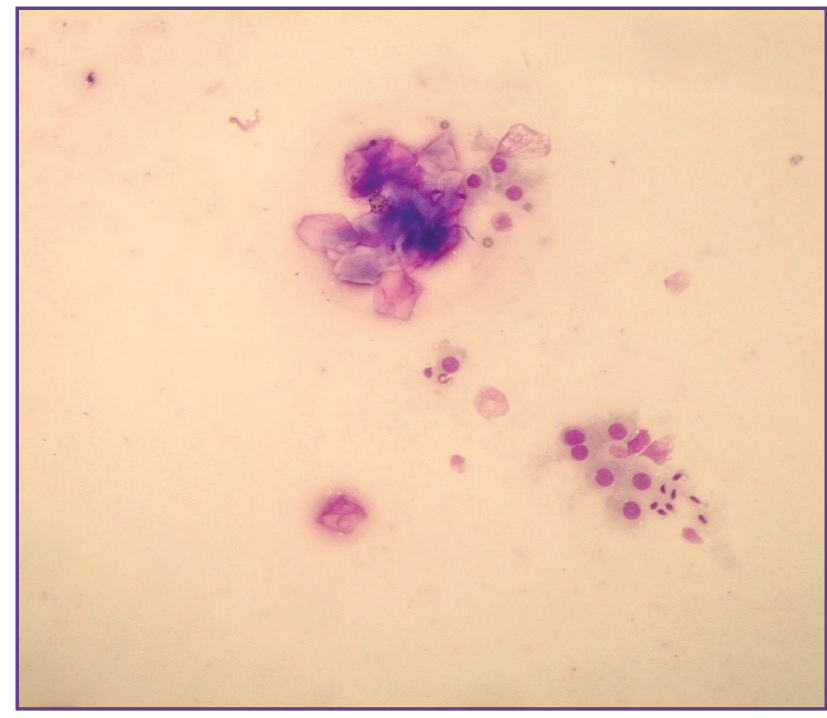

Fig. 1: Photomicrograph showing anucleate squamous epithelial cells admixed with testicular spermatogenetic cells.(MGG,1000X).

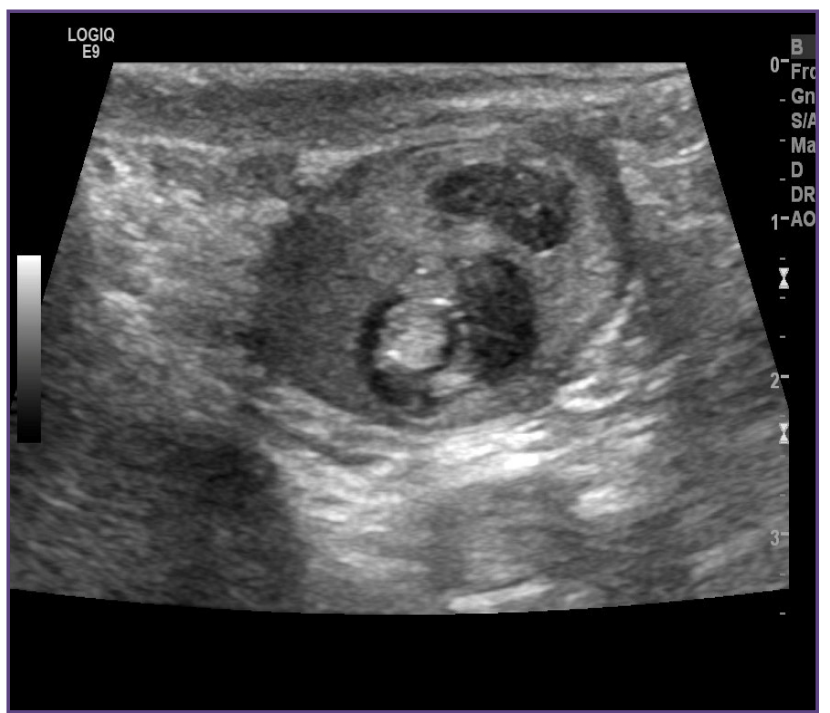

Fig. 2: Sonogram showing a round mass with concentric rings of alternating echogenecity.

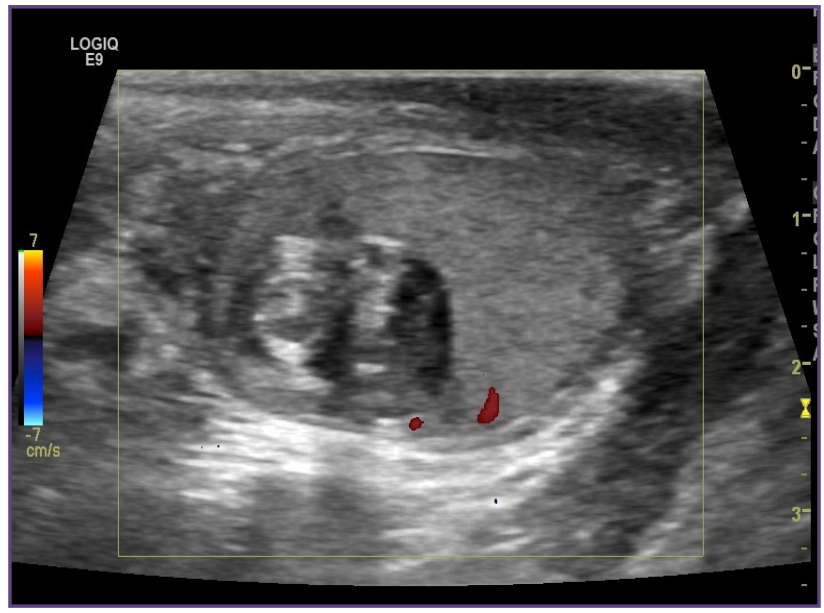

Fig. 3: Color Doppler Sonogram showing minimal color doppler from within the mass.

do not have a risk of recurrence or metastasis. ${ }^{[2]}$ It poses a clinical dilemma, as such testicular mass lesion gives an impression of it being a testicular tumour. [3] The most important of which is a teratoma, which has a strong malignant potential. But the absence of mesodermal and endodermal component in cytology and serum tumour markers being within normal range, rules out the possibility of it being a teratoma..

Malek RS et al(1986) ${ }^{[4]}$ described that testicular epidermoid cyst presenting as painless swelling, however, in the present case the patient complained of pain in the swelling. Macroscopically, these are cystic and smooth. Cytologically it shows anucleated clumps of squamous epithelial cells admixed with the native testicular cells. Cytology along with various other tools help us to reach a diagnosis. The include (1) absence of elevated tumour markers; (2) ultrasound comprises of hyperechoic heterogenous sonographic pattern which gives "onion skin appearance; (3) MRI typically showing " bull's eye" appearance i.e. a high intensity mid-zone which consist of scaly squamous cells and periphery zone of low intensity in T1 and T2 due to compact keratin fibres; (4) no Doppler vascularization. ${ }^{[5]}$ Although the sonographic findings are strongly suggestive but they are not completely diagnostic of an epidermoid cyst. The surgeon has to take the help of an intra-operative frozen section to plan the further course of treatment. 
The treatment of choice is excision of the cyst along with surrounding testicular parenchyma to exclude any accompanying teratomatous component or malignant germ cell neoplasia. Postoperative monitoring is always recommended. ${ }^{[6]}$ However, in our case the patient refused the surgical option and a diagnosis was rendered on the classical cytological features along with sonographic " onion skin" appearance .The case is presented because its diagnosis on FNAC is a rare entity and it provided a rapid and conclusive diagnosis to the surgeon, thus, saving a young patient from undergoing an orchidectomy.

\section{References}

1. Loberant N, Bhatt S, Messing E et al. Bilateral Testicular Epidermoid Cysts :A rare Tumor. Journal of Clinical Imaging Science. 2011A;1:4.
2. Somuncu S, Cakmak M, Atasoy $P$ et al. Testicular epidermoid cyst and organ preserving surger y. Journal of Indian Association of Pediatric Surgery .2006;11:99-100

3. Maizlin ZV, Belenky A, Baniel J etc al. Epidermoid cyst and Teratoma of the testis: sonographic and histologic similarities. Journal of Ultrasound Medicine .2005;24:1403-9

4. Malek RS, Rosen JS, Farrow GM. Epidermoid cyst of testis: a critical analysis . British Journal of Urology.1986;58;55-59.

5. Fernandez JA, Santiago SA, Diez BC etc al.Intratesticular Epidermoid Cyst:A rare Tumor. Journal of Clinical Medicine Research.2010;2: 281-283.

6. Heidenreich A, Egelmann UH, Vietsch HV et al. Organ preserving surgery in testicular epidermoid cysts. Journal of Urology.1995; 153: 1147-1150.

*Corresponding author:

Dr Dilip Kumar, Flat no.- G3, Plot no.- 617,Sector, Vaishali, Ghaziabad (U.P.)- 201010 India

Phone: +91 9810758472

Email: drkum ardil ip@gma il.c om

Date of Submission : 09.01.2017

Date of Acceptance : 12.02.2017

Financial or other Competing Interests: None.
Date of Publication : 28.03.2017 